\title{
Effects of Duloxetine Treatment on Brain Response to Painful Stimulation in Major Depressive Disorder
}

\author{
Marina López-Solà ${ }^{1,2}$, Jesus Pujol*, 1,3, Rosa Hernández-Ribas' ${ }^{1,4,5}$, Ben J Harrison ${ }^{1,6}$, Oren Contreras- \\ Rodríguez $^{1,7}$, Carles Soriano-Mas ${ }^{1,7}$, Joan Deus ${ }^{1,8}$, Héctor Ortiz', José M Menchón ${ }^{4,5}$, Julio Vallejo ${ }^{2,5}$ \\ and Narcís Cardoner ${ }^{1,4,5}$
}

'Institut d'Alta Tecnologia-PRBB, CRC Hospital del Mar, Barcelona, Spain; ${ }^{2}$ Faculty of Medicine, Department of Clinical Sciences, University of Barcelona, Barcelona, Spain; ${ }^{3}$ Networking Research Center on Bioengineering, Biomaterials and Nanomedicine (CIBER-BBN), Barcelona, Spain; ${ }^{4}$ Department of Psychiatry, Bellvitge University Hospital-IDIBELL, Barcelona, Spain; ${ }^{5}$ Instituto de Salud Carlos III, Centro de Investigación en Red de Salud Mental (CIBERSAM), Madrid, Spain; ' Department of Psychiatry, Melbourne Neuropsychiatry Centre, The University of Melbourne, Melbourne, Victoria, Australia; ${ }^{7}$ Human Pharmacology and Neurosciences Department, Fundació IMIM-PRBB, Barcelona, Spain; ${ }^{8}$ Department of Clinical and Health Psychology, Autonomous University of Barcelona, Barcelona, Spain

\begin{abstract}
Major depressive disorder (MDD) is characterized by a constellation of affective, cognitive, and somatic symptoms associated with functional abnormalities in relevant brain systems. Painful stimuli are primarily stressful and can trigger consistent responses in brain regions highly overlapping with the regions altered in MDD patients. Duloxetine has proven to be effective in treating both core emotional symptoms and somatic complaints in depression. This study aimed to assess the effects of duloxetine treatment on brain response to painful stimulation in MDD patients. A total of 13 patients and a reference group of 20 healthy subjects were assessed on three occasions (baseline, treatment week I, and week 8) with functional magnetic resonance imaging (fMRI) during local application of painful heat stimulation. Treatment with duloxetine was associated with a significant reduction in brain responses to painful stimulation in MDD patients in regions generally showing abnormally enhanced activation at baseline. Clinical improvement was associated with painrelated activation reductions in the pregenual anterior cingulate cortex, right prefrontal cortex, and pons. Pontine changes were specifically related to clinical remission. Increased baseline activations in the right prefrontal cortex and reduced deactivations in the subgenual anterior cingulate cortex predicted treatment responders at week 8 . This is the first fMRI study addressed to assess the effect of duloxetine in MDD. As a novel approach, the application of painful stimulation as a basic neural stressor proved to be effective in mapping brain response changes associated with antidepressant treatment and brain correlates of symptom improvement in regions of special relevance to MDD pathophysiology.

Neuropsychopharmacology (20 I0) 35, 2305-23 I7; doi: I0.1038/npp.2010.108; published online 28 July 2010
\end{abstract}

Keywords: major depressive disorder; $\mathrm{AMRI}$; pain; brain; treatment; duloxetine

\section{INTRODUCTION}

Major depression is a frequent and disabling psychiatric disorder (World Health Organization, 2001) characterized by a constellation of mood, cognitive, psychomotor, and somatic symptoms (American Psychiatric Association, 2000). Neuroimaging has contributed to current understanding of major depressive disorder (MDD) pathophysiology, suggesting a global misbalance in the neural systems that serve such major aspects of brain function (Drevets, 2000; Mayberg, 2003; Price and Drevets, 2010; Sheline, 2003).

*Correspondence: Dr J Pujol, Department of Magnetic Resonance, CRC Hospital del Mar, 25-29 Passeig Marítim, 08003 Barcelona, Spain, Tel: + 349322121 80, Fax: + 3493 221 21 81, E-mail: jpujo|@crccorp.es Received II February 2010; revised 3 May 2010; accepted 21 June 2010
Painful stimuli are primarily salient and threatening, and normally provoke rapid withdrawal and stress-related responses (Price, 2000). Functional magnetic resonance imaging (fMRI) has confirmed the involvement of a widespread brain network in processing noxious stimulation including the somatosensory system, limbic and paralimbic regions related to the affective experience of pain, and prefrontal regulatory areas modulating the entire brain response (Apkarian et al, 2005; López-Solà et al, 2010; Wiech et al, 2008a). As painful stimulation typically evokes an integrated response involving brain regions that are relevant to MDD pathophysiology (Drevets, 2000; Mayberg, 2003; Sheline, 2003), functional neuroimaging using pain paradigms may provide the opportunity to challenge such regions, both for the purpose of investigating MDD abnormalities in response to a basic neural stressor (Bär et al, 2007; Strigo et al, 2008), and also, potentially, 
for providing objective biological markers of the effects of antidepressant treatment.

The interaction between major depression and pain symptoms appears to be a growing focus of interest in MDD research. Clinical pain complaints have significantly higher mean prevalence in MDD patients (65\% as reviewed by Bair et al, 2003) compared with the general population (24-37\%, Regier et al, 1984), and furthermore, the presence of pain complaints in MDD patients is associated with greater MDD severity and refractoriness (Bair et al, 2003). In addition, mood symptoms and somatic pain in depression have been shown to improve simultaneously (Blier and Abbott, 2001). Recent evidence suggests that dual serotonine and norepinephrine reuptake inhibitors (such as duloxetine, Trivedi et al, 2008) are effective antidepressants relieving both mood symptoms and somatic complaints in MDD (Gupta et al, 2007). Specifically for the case of duloxetine, several studies have suggested that early symptomatic improvement may already be noticeable after 1-2 weeks of treatment (Hirschfeld et al, 2005; Nemeroff et al, 2002; Shelton et al, 2007). In contrast to the described close clinical association between major depression and pain complaints, it has been suggested that depressed patients are less sensitive to experimentally induced pain on the skin (Bär et al, 2005), although the neural basis for this paradox is still rather unknown (Bär et al, 2007). In addition, the effect of antidepressant treatment on experimental thermal pain perception and the associated brain responses has not been explored to date.

Neuroimaging techniques have been successfully used to assess the effects of various drugs on baseline brain metabolism and on the cerebral response to specific cognitive and emotional stimuli (Drevets et al, 2008a; Mayberg, 2003; Rigucci et al, 2009). Nevertheless, despite its potential interest, it is noteworthy that imaging paradigms based on painful stimulation have not been used to investigate the effects of antidepressant agents.

This fMRI study aimed to assess the effects of duloxetine treatment on brain response to heat painful stimulation in MDD patients. The study design included an fMRI assessment at baseline - pretreatment-and assessments following 1 week and 8 weeks of treatment. Brain activations in MDD patients were compared with the activations obtained in a reference group of healthy subjects who were also assessed three times to control for task-repetition effects. Brain correlates of clinical improvement were investigated for both core and somatic depression symptoms. A specific analysis was also conducted to identify baseline brain imaging predictors of clinical response to treatment. Finally, correlations between experimental pain ratings and fMRI treatment effects on brain responses to pain were also investigated.

\section{MATERIALS AND METHODS}

\section{Subjects}

Fifteen patients were consecutively recruited from the Mood Disorders Unit of the University Hospital of Bellvitge. All patients met DSM-IV criteria for MDD with no psychotic features. MDD patients were assessed using the Structured Clinical Interview for DSM-IV Axis I Disorders-Clinician
Version (SCID; First et al, 1997) that was conducted by two senior psychiatrists who reached a consensus for all items and also for the compliance of inclusion/exclusion criteria. At inclusion, all patients had a Hamilton Depression Scale (HAM-D 17; Hamilton, 1960, 1967) score $\geqslant 18$. Exclusion criteria included the presence or history of other axis I diagnoses and relevant medical or neurological disorders including chronic pain syndromes, and abnormal clinical MRI on radiological inspection. From the original 15 -subject sample, one patient was excluded as she was unable to complete the first fMRI session and another patient voluntarily left the study after the first MRI assessment. The remaining 13 patients underwent both basal and 8-week reassessment and made up our final study patient sample. One of these 13 patients, however, was unable to complete the week $1 \mathrm{fMRI}$ session as she felt temporarily sick on the assessment day. Table 1 shows the clinical characteristics of the final 13-patient sample.

A comparison group of 21 healthy volunteers also participated in the study. A SCID was carried out to discard the presence of axis I disorders, and also a complete medical interview was performed to exclude subjects with relevant medical or neurological disorders, history of substance abuse and psychiatric illness, and chronic pain syndromes. From the original sample, one subject was excluded due to excessive movement inside the scanner (translation movement in the $z$ axis $>3 \mathrm{~mm}$ ) during the baseline fMRI assessment. A total of 20 subjects made up the control sample, although technical issues with the thermal stimulator compromised the use of one subject's fMRI data from the week 1 assessment. Age, gender, handedness, and years of education are reported in Table 1. MDD patients and control subjects did not differ on these variables. All patients and control subjects gave written informed consent to participate in the study, which was approved by the research and ethics committee of the University Hospital of Bellvitge.

\section{Study Design}

For all patients, the study included an antidepressant medication washout of 15 days before treatment onset. Patients received antidepressant treatment with oral duloxetine, a serotonin-norepinephrine reuptake inhibitor, starting at $60 \mathrm{mg}$ per day in a single dosage for 4 full weeks. After week 4 , dose increases (up to $120 \mathrm{mg}$ per day) were prescribed on the basis of patients' response when both senior psychiatrists coincided in their clinical judgment. All patients underwent weekly clinical assessments throughout the study period. The following clinical scales were used to assess mood, somatic, and general treatment-related response: HAM-D-17 (Hamilton, 1960, 1967), Brief Pain Inventory (Cleeland and Ryan, 1994), Symptom QuestionnaireSomatic Subscale (Kellner, 1987), and the Clinical Global Impression of Severity (Guy, 1976).

The study consisted of three fMRI assessments, which were carried out at week 0 (before treatment), and following 1 and 8 weeks of treatment. Control subjects also underwent fMRI assessments at baseline, week 1 and week 8, which served to control for task-repetition effects on brain responses to painful stimulation. 
Table I Main Characteristics of the Study Sample

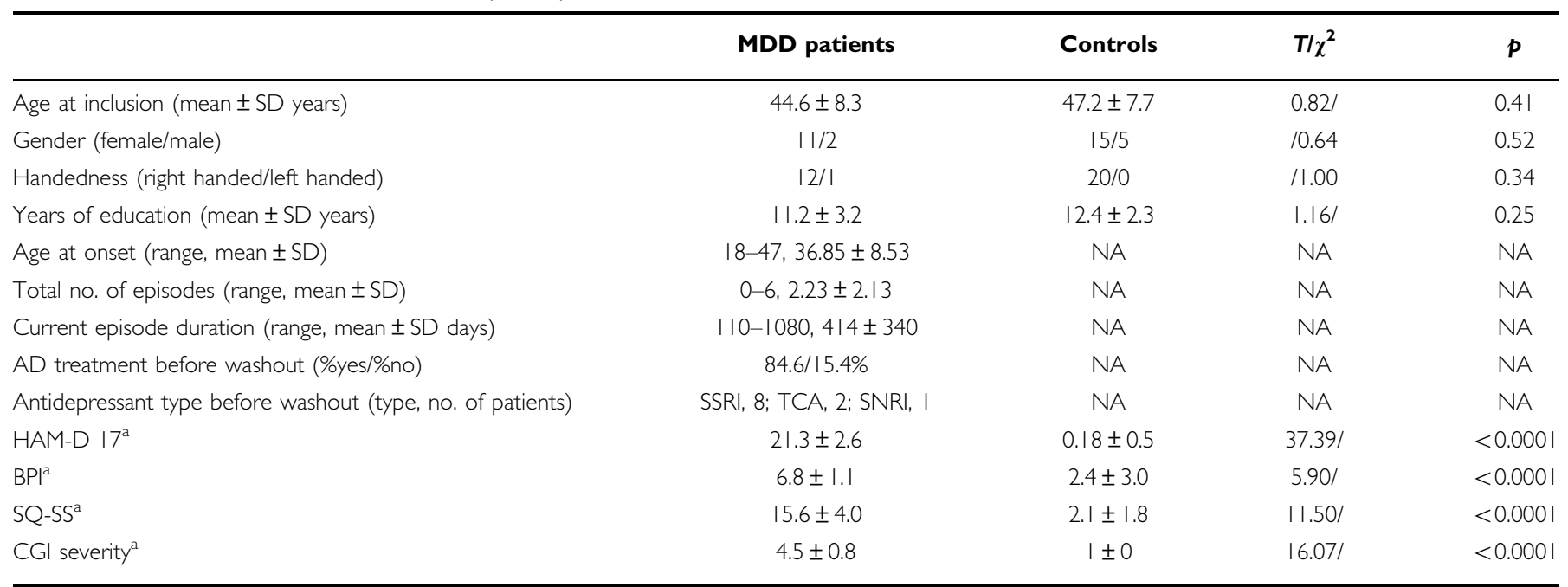

Abbreviations: AD, antidepressant; SSRI, selective serotonin reuptake inhibitor; TCA, tricyclic antidepressant; SNRI, serotonin-norepinephrine reuptake inhibitor; HAM-D 17, Hamilton Depression Rating Scale, I7-item version; BPI, Brief Pain Inventory, maximum pain during the week; SQ-SS, Symptom Questionnaire, Somatic Subscale; CGI Severity, Clinical Global Impression of Severity, NA, nonapplicable.

${ }^{\text {aAll }}$ measurements were obtained at baseline fMRI (before treatment onset).

\section{Stimulus}

The Contact Heat-Evoked Potential Stimulator (CHEPS) system was used, which has been designed to provide controlled thermal stimuli (CHEPS; Medoc, Advanced Medical Systems, Israel). This system is able to provoke pain by direct stimulation of $\mathrm{A} \Delta$ and $\mathrm{C}$ nociceptive fibers on a relatively large skin area (by the $27 \mathrm{~mm}$ diameter thermode) through very rapid local heating $\left(70^{\circ} \mathrm{C}\right.$ per second rate). In our experiment, painful heat stimulation was applied to the right volar forearm in 10-s blocks each including eleven $50^{\circ} \mathrm{C}$ spikes (full-width at half-maximum duration of each spike: $125 \mathrm{~ms}$ ), starting from a baseline temperature of $32^{\circ} \mathrm{C}$.

In a preliminary session, each subject was trained to rate their perceived pain intensity using a numerical rating scale ranging from 0 ('no pain') to 100 ('the worst pain'), and perceived unpleasantness using a nine-point verbal descriptor scale ranging from 'not at all unpleasant' to 'extremely unpleasant' when receiving two full (11 spikes) stimulation blocks.

\section{fMRI Pain Paradigm}

A block design was used consisting of three conditions per stimulation cycle repeated 12 times during a 7-min run: a rest condition with pseudorandom variable duration (duration range: $12-26 \mathrm{~s}$ ), a 6-s anticipatory condition that began with a brief auditory stimulus (600-ms tone) cuing the subsequent pain condition, and the actual 10-s painful condition (involving the application of the $50^{\circ} \mathrm{C}$ spike stimuli). Immediately after the entire fMRI sequence was completed, each subject rated the overall pain intensity and unpleasantness experienced during the 12 painful stimulation cycles.

\section{MRI Acquisition}

A 1.5 Tesla Signa system (General Electric, Milwaukee, WI) equipped with an eight-channel phased-array head coil and single-shot echoplanar imaging (EPI) software was used. Functional sequences consisted of gradient-recalled acquisitions in the steady state (time of repetition, $2000 \mathrm{~ms}$; time of echo, $50 \mathrm{~ms}$; pulse angle, $90^{\circ}$ ) within a field of view of $24 \mathrm{~cm}$, a $64 \times 64$ pixel matrix, and a slice thickness of $4 \mathrm{~mm}$ (interslice gap, $1.5 \mathrm{~mm}$ ). Twenty-two slices parallel to the anterior-posterior commissure line covered the whole brain. The sequence included four additional dummy volumes to allow the magnetization to reach equilibrium.

\section{Image Preprocessing}

Imaging data were processed using MATLAB version 7 (The MathWorks, Natick, MA) and Statistical Parametric Mapping software (SPM5; The Welcome Department of Imaging Neuroscience, London). Image preprocessing involved motion correction, spatial normalization, and smoothing using a Gaussian filter (full-width at half-maximum, $8 \mathrm{~mm}$ ). Data were normalized to the standard SPM-EPI template and resliced into $2 \mathrm{~mm}$ isotropic voxels in Montreal Neurological Institute space.

\section{Statistical Analyses}

Brain responses to painful stimulation and group comparisons. Our analyses aimed to identify (1) betweengroup differences in brain activation at baseline (pretreatment), (2) treatment effects at week 1, (3) treatment effects at week 8 , and (4) the pattern of correlations between clinical measurements (and experimental pain ratings) and fMRI treatment effects. 
Single-subject first-level analyses were implemented in SPM5 to model fMRI time series using four box-car regressors; two representing anticipation and painful stimulation periods, and two representing the rest period divided into two parts: a 6-s post-stimulation period and a variable $(6-20 \mathrm{~s})$ remaining rest period, considering a hemodynamic delay of $4 \mathrm{~s}$. We explicitly modeled the post-stimulation period (6-s interval after each stimulation block), as brain activation may persist during this period (López-Solà et al, 2010; Moulton et al, 2005; Pujol et al, 2009) and may therefore alter the reference baseline with noncontrolled remaining activation. A contrast image showing fMRI signal differences between the painful stimulation condition and the second part of the rest period (modeled by the corresponding box-car regressors in SPM5) was calculated for each subject.

The contrast images were then carried forward to subsequent second-level random-effects (group) analyses. One-sample $t$-statistic maps were calculated to obtain baseline (pretreatment) activation (and deactivation) patterns for each group, and a two-sample $t$-test was performed to map between-group baseline brain activation (and deactivation) differences. To assess treatment effects on brain response to pain, we performed two separate (week 1 and week 8) second-level mixed ANOVA analyses including the within-subject factor 'time moment' (baseline vs reassessment), and the intersubject factor 'group' (patient $v s$ control) as independent variables. Group-by-time interaction $t$-statistic maps were then calculated to identify activation changes that were greater in MDD patients than in healthy control subjects.

For the sake of simplicity we do not report treatment effects on the anticipatory period (before actual painful stimulation onset) as the complete pattern followed the same direction as treatment effects occurring in response to actual painful stimulation, thus adding only marginal information considering the purposes of the study and space limitation.

Correlation analyses between clinical and fMRI treatment effects. Specific correlation analyses were performed in SPM5 to test for linear relationships between clinical improvement in the two symptomatic dimensions of interest, ie, core emotional and somatic symptoms (measured as reductions in Core (items 1, 2, 3, 7, and 8) and Somatization Subscales $(10,11,12,13,15$, and 17) of the HAM-D 17) and fMRI brain activation changes at weeks 1 and 8 in relation to baseline. These exploratory correlation analyses were carried out for regions showing significant treatment effects at weeks 1 and 8 (regions showing significant interaction results from the mixed ANOVA models (reported in Table 3).

An exploratory two-sample $t$-test analysis was additionally performed to assess treatment-related fMRI activation changes associated with remission (binary factor defined by HAM-D 17 scores below 7 or $\geqslant 7$ ), by comparing the 'baseline minus week 8 activation' contrast images between remitting and nonremitting patients (for the regions showing significant treatment effects after 8 weeks).

Imaging predictors of clinical response. To specifically test whether baseline (pretreatment) regional activations were able to predict positive clinical responders to duloxetine (measured as 50\% reductions in the HAM-D 17 total score from baseline to week 8), we performed an exploratory twosample $t$-test analysis to compare the patterns of baseline activation of clinical responders and nonresponders (also for the regions showing significant treatment effects after 8 weeks).

Correlation analyses between pain ratings and $f M R I$ treatment effects. To investigate the relationship between experimental pain perception and brain activation in regions showing significant treatment effects in MDD, we conducted additional correlation analyses in SPM5. For both intensity and unpleasantness ratings, two models were estimated in MDD patients to: (1) correlate changes in subjective pain ratings with changes in fMRI responses from baseline to week 8 and (2) correlate subjective pain scores and fMRI brain response measurements at week 8 . The analyses were carried out for regions showing significant treatment effects at week 8 (regions showing significant interaction results from the mixed ANOVA model (reported in Table 3).

Thresholding criteria. Baseline group activation (and deactivation) results were thresholded at $p_{\text {False }}$ Discovery Rate-FDR $<0.05$ whole-brain corrected. Between-group differences, interaction effects, and correlation analyses were considered significant when involving a minimum cluster extension of 200 voxels $\left(1600 \mathrm{~mm}^{3}\right)$ at $p<0.05$ uncorrected. The use of a combined $p$-value/cluster extension thresholding approach has been suggested to provide a more desirable balance between type I and type II error rates (Lieberman and Cunningham, 2009). For the brainstem (as it is a small structure), a more lenient extension threshold (cluster $>100$ voxels) was used.

\section{RESULTS}

\section{Clinical Response to Treatment}

Supplementary Table S1 shows patients' response to treatment measured as changes in the selected clinical scales. All in all, a modest, though significant, improvement was observed after 1 week of treatment in most scales. Differences were robust after 8 weeks of treatment in all measurements. At the end of the 8-week treatment period, nine out of thirteen patients met the criterion for clinical response to treatment and six of them met the criterion for clinical remission.

\section{Subjective Pain Scores During fMRI}

Major depressive disorder patients and control subjects did not differ as to the reported amount of subjective pain intensity (mean \pm SD for patients: $5.8 \pm 2.4$ and control subjects: $6.7 \pm 1.8 ; t=1.27, p=0.21$ ) and unpleasantness (patients, $3.7 \pm 1.7$; control subjects, $4.6 \pm 1.5 ; \quad t=1.6$, $p=0.13$ ) during baseline fMRI assessment, although patients showed the lowest values for both measurements. We found no significant group-by-time interaction effect when comparing baseline and week 1 subjective pain scores (intensity $\mathrm{F}=0.72, \quad p=0.40 ;$ unpleasantness $\mathrm{F}=0.04$, 
$p=0.85)$. Nevertheless, significant group-by-time interactions for pain intensity $(\mathrm{F}=5.21, p=0.03)$ and unpleasantness $(\mathrm{F}=7.64, p=0.01)$ were found when comparing baseline and week 8 measures. Post hoc comparisons indicated that although control subjects did not show significant changes from baseline to week 8 reassessment (intensity: $t=-1.24, p=0.23$; unpleasantness: $t=-1.68$, $p=0.11$ ), patients had a tendency to report increased pain intensity $(t=1.86, p=0.088)$ and showed significantly higher unpleasantness scores $(t=2.38, p=0.035)$ after this period. Interestingly, we found a significant correlation between the reduction in core emotional MDD symptoms after treatment (baseline to week 8) and the enhancement of pain unpleasantness ratings $(r=-0.59, p=0.03)$, and a weaker association for perceived intensity $(r=-0.44$, $p=0.13)$.

\section{Brain Response to Painful Heat Stimulation: Baseline Assessment}

Baseline brain responses to painful heat stimulation are reported in Table 2 and Figure 1. For both study groups, brain response was characterized by significant activation in bilateral insulae extending to basal ganglia, parietal and frontal opercula, ACC-supplementary motor area (SMA), prefrontal cortex, and cerebellum. The patient group additionally showed significant activation in the middle temporal gyrus (Brodmann area (BA) 22) and in the hypothalamic-midbrain region. Significant reductions in fMRI signal during painful stimulation compared with rest (deactivations) were only identified in the control subject group and involved the subgenual-pregenual ACC and extended medial prefrontal cortex.

Compared with control subjects, the MDD group showed greater baseline activation in bilateral insulae, frontal and temporal opercula, ventral basal ganglia, hypothalamic region, medial prefrontal cortex, left hippocampus, and middle temporal gyrus (Table 2; Figure 2a). Patients also showed significantly reduced deactivation (ie, abnormal persistence of activity during stimulation) in a large area involving the subgenual and pregenual ACC and extended medial prefrontal regions (Table 2; Figure $2 \mathrm{~b}$ ). We found no regions of significantly greater activation in the control group when compared with MDD patients.

\section{Treatment Effects on Brain Response to Painful Stimulation}

Significant group-by-time interactions were observed from baseline to week 1 fMRI assessments revealing a general effect of brain activation reductions in MDD patients and the opposite tendency in control subjects (Table 3; Supplementary Table S2; Figure 3; Supplementary Figure S1). Regions showing a significant interaction effect largely coincided with regions showing enhanced baseline activation (or reduced deactivation) in MDD patients compared with control subjects (bilateral insulae, frontal and temporal opercula, basal ganglia, hypothalamic region, ventromedial prefrontal cortex, left hippocampus, middle temporal gyrus, and subgenual-pregenual ACC regions). In addition, groupby-time interactions were significant in the dorsolateral prefrontal cortex (BA 9/10).
Table 2 Brain Response to Painful Heat in MDD and Control Subjects and Between-Group Differences

\begin{tabular}{|c|c|c|c|c|}
\hline Controls activations & $\mathbf{X}: \mathbf{Y}: \mathbf{Z}$ & $k$ & $t$ & PFDR \\
\hline \multirow[t]{2}{*}{ Insula-opercula } & $-360-8$ & 2252 & 6.14 & 0.008 \\
\hline & 40342 & $207 \mid$ & 7.39 & 0.007 \\
\hline \multirow[t]{2}{*}{ Prefrontal cortex } & $-3632 \quad 12$ & 132 & 4.20 & 0.022 \\
\hline & 463436 & 581 & 5.26 & 0.010 \\
\hline \multirow[t]{2}{*}{ Basal ganglia } & $-30-8-6$ & 302 & 5.10 & 0.011 \\
\hline & 3066 & 233 & 4.87 & 0.013 \\
\hline ACC-SMA & 62036 & 1666 & 4.47 & 0.018 \\
\hline Cerebellum & $4-50-18$ & 468 & 5.28 & 0.010 \\
\hline Controls deactivations & $\mathbf{X}: \mathbf{Y}: \mathbf{Z}$ & $k$ & $t$ & PFDR \\
\hline Subg., Preg. ACC & $-246-14$ & 1446 & 5.59 & 0.003 \\
\hline Patients activations & $X: Y: Z$ & k & $t$ & $P_{\text {FDR }}$ \\
\hline \multicolumn{5}{|l|}{ Insula-opercula } \\
\hline & $-42-100$ & 4056 & 7.37 & 0.037 \\
\hline & $50-84$ & 3990 & 6.68 & 0.037 \\
\hline \multirow[t]{2}{*}{ Prefrontal cortex } & $-58-242$ & 200 & 4.36 & 0.038 \\
\hline & 54056 & 305 & 5.57 & 0.037 \\
\hline \multirow[t]{2}{*}{ Basal ganglia } & -3060 & 354 & 4.63 & 0.041 \\
\hline & 28142 & 414 & 4.43 & 0.041 \\
\hline ACC-SMA & $-8-1244$ & 2100 & 5.75 & 0.037 \\
\hline Cerebellum & $4-46-24$ & 1717 & 6.10 & 0.037 \\
\hline Middle temporal gyrus & $-68-42-8$ & 298 & 5.30 & 0.037 \\
\hline Hypothal. region-midbrain & $-4-4-14$ & 132 & 3.89 & 0.043 \\
\hline Patients $>$ controls & $\mathbf{X}: \mathbf{Y}: \mathbf{Z}$ & $k$ & $t$ & Punc. \\
\hline \multicolumn{5}{|l|}{ Increased activations } \\
\hline \multirow[t]{2}{*}{ Post. Ins.-Temp. Operc.-HPC } & $-46-26-10$ & 1249 & 3.18 & 0.002 \\
\hline & $40-14-6$ & 2042 & 4.24 & $<0.0005$ \\
\hline Ant. Ins.-frontal Operc. & -24246 & 585 & 3.01 & 0.002 \\
\hline $\begin{array}{l}\text { Basal G.-Med. PFC-Hypothal. } \\
\text { region }\end{array}$ & $-416-16$ & 1146 & 3.50 & 0.001 \\
\hline Middle temp. gyrus & $-62-424$ & 569 & 3.28 & 0.001 \\
\hline \multicolumn{5}{|l|}{ Reduced deactivations } \\
\hline Subg., Preg. ACC & $418-18$ & 2185 & 3.91 & $<0.0005$ \\
\hline
\end{tabular}

Abbreviations: $k$, cluster size; FDR, false discovery rate whole-brain corrected; Unc., uncorrected; ACC, anterior cingulate cortex; SMA, supplementary motor area; Hypothal., hypothalamic; Post., posterior; Ins., insula; Temp., temporal; Operc., operculum; HPC, hippocampus; Ant., anterior; Med., medial. Subg., subgenual; Preg., pregenual.

Coordinates (X: Y: Z) are given in Montreal Neurological Institute Atlas space.

Significant group-by-time interactions were again observed from baseline to week 8 , with group changes showing the direction observed in week 1 interaction analysis and involving a similar region network (Table 3; Supplementary Table S3; Figure 3; Supplementary Figure S1). In addition, an interaction effect was observed along the brainstem including anterior and posterior parts of the pons.

\section{Correlations Between Clinical and fMRI Treatment Effects}

A specific analysis was carried out to assess the correlation between clinical improvement in both core emotional and 


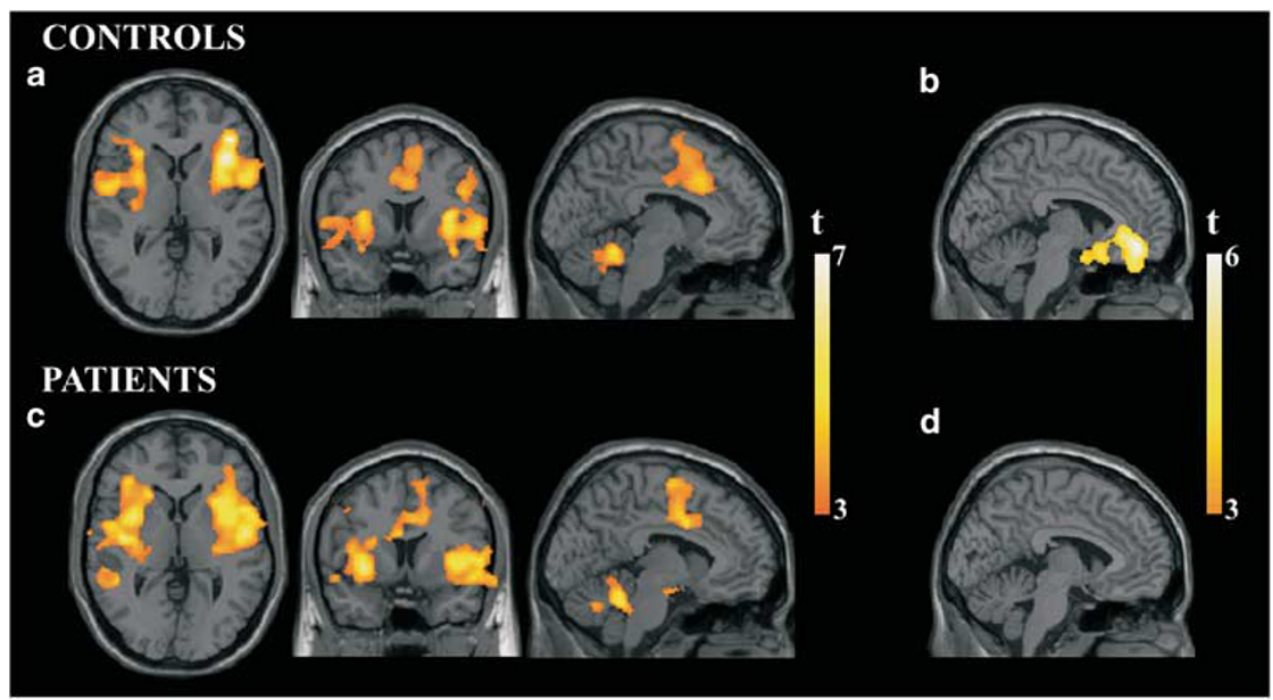

Figure I Brain activation and deactivation patterns for healthy controls and MDD patients in response to painful heat stimulation. (a) Activation pattern for healthy controls. (b) Deactivation pattern for healthy controls. (c) Activation pattern for MDD patients. (d) Deactivation pattern for MDD patients. All depicted voxels show $p<0.05_{\mathrm{FDR}}$ corrected. Images are shown in the neurological convention.

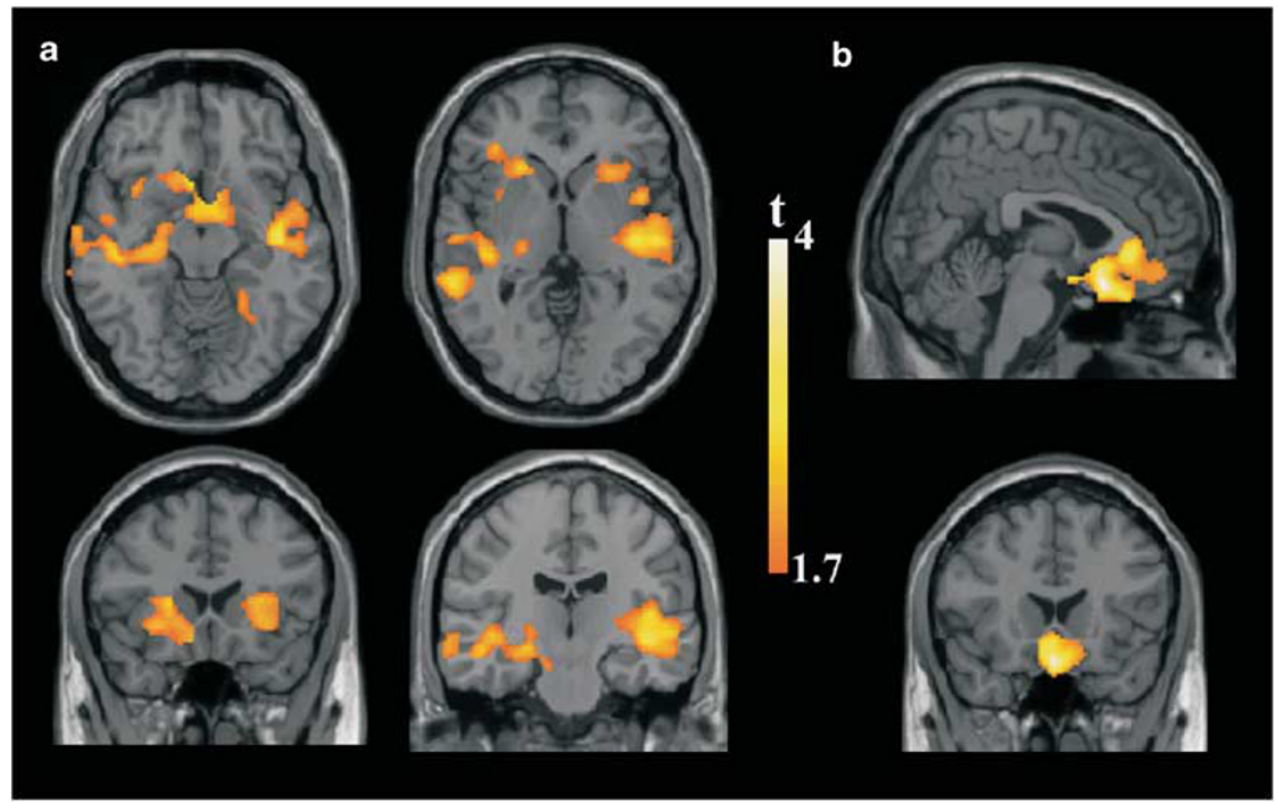

Figure 2 Regions showing greater activation during painful heat stimulation in Patients. (a) Patients > controls, assessed within the activation pattern of the patient group. (b) Patients > controls, assessed within the deactivation pattern of the control group. Images are shown in the neurological convention. Extension threshold: 200 voxels. $p$-Voxel level $<0.05$ uncorrected.

somatic symptoms (using the Core and Somatization Subscales of the HAM-D 17, respectively) and fMRI treatment-related changes. This analysis was limited to the regions that showed significant treatment effects. We found that reductions in core MDD symptoms after 1 week of treatment were significantly correlated with activation reductions (ie, deactivation increases) in the pregenual ACC region (ventral BA24 and BA32), which showed an abnormal persistence of activity during stimulation at baseline. Reductions in somatic symptoms were significantly correlated with activation reductions in the right dorsolateral prefrontal cortex (BA 9, Supplementary Table S4; Supplementary Figure S2).

Improvement in core MDD symptoms after 8 weeks of treatment correlated with activation reductions in the right dorsolateral prefrontal cortex (BA 9) and left insuloopercular region, whereas the improvement in somatic symptoms after this period was associated with activation reductions in the pons (Supplementary Table S4; Supplementary Figure S2).

The categorical analysis assessing fMRI treatment-related changes associated with remission showed that remitting 
Table 3 Treatment Effects on Brain Response to Painful Stimulation

\begin{tabular}{|c|c|c|c|c|}
\hline Region & $\mathbf{X}: \mathbf{Y}: \mathbf{Z}$ & k & $\boldsymbol{t}$ & Punc. \\
\hline \multicolumn{5}{|c|}{ Week I treatment effects. Interaction effects (baseline to week I) } \\
\hline \multirow[t]{2}{*}{ Insula-Operc--HPC } & $-408 \mid 4$ & 701 & 3.46 & 0.001 \\
\hline & $48-10-6$ & 761 & 2.68 & 0.005 \\
\hline \multirow[t]{2}{*}{ Basal ganglia } & -12822 & 204 & 2.71 & 0.004 \\
\hline & 12422 & 395 & 2.69 & 0.005 \\
\hline Hypothal. region-Med. PFC & $6-2-16$ & 355 & 3.88 & $<0.000$ । \\
\hline Middle temp. gyrus & $-66-360$ & 765 & 3.55 & $<0.000$ । \\
\hline Subg. Preg. ACC & $-650-10$ & 5515 & 3.86 & $<0.000$ । \\
\hline \multirow[t]{2}{*}{ Dorsolat. PFC } & -362234 & 1097 & 2.78 & 0.004 \\
\hline & 203426 & 1014 & 3.03 & 0.002 \\
\hline \multicolumn{5}{|c|}{ Week 8 treatment effects. Interaction effects (baseline to week 8) } \\
\hline Anterior Insula-frontal Op. & $-4620-2$ & 1039 & 2.94 & 0.002 \\
\hline \multirow[t]{2}{*}{ Posterior insula-Temp Op. } & $-44-24-6$ & 281 & 3.17 & 0.001 \\
\hline & $44-16-6$ & 315 & 2.82 & 0.003 \\
\hline Hypothal. region-Med. PFC & $4-2-16$ & 358 & 3.05 & 0.002 \\
\hline Middle Temp. gyrus & $-60-424$ & 473 & 3.36 & 0.001 \\
\hline Subg. Preg. ACC & $222-24$ & 1368 & 3.70 & $<0.000$ \\
\hline \multirow[t]{2}{*}{ Dorsolat. PFC } & $-3048 \quad \mid 4$ & 219 & 2.84 & 0.003 \\
\hline & 342634 & 1002 & 3.40 & 0.001 \\
\hline Inferior pons & $2-38-36$ & 1717 & 3.08 & 0.002 \\
\hline Superior pons & $0-20-24$ & 1717 & 2.92 & 0.002 \\
\hline
\end{tabular}

Abbreviations: k, cluster size; Unc., uncorrected; Operc., opercula; Op., operculum; HPC, hippocampus; Hypothal., hypothalamic; Med., medial; PFC, prefrontal cortex; Temp., temporal; Subg., subgenual; Preg., pregenual; ACC, anterior cingulate cortex; Dorsolat., dorsolateral.

Coordinates ( $X: Y: Z)$ are given in Montreal Neurological Institute Atlas space. (compared with nonremitting) patients had greater activation reductions in the pons after 8 weeks of treatment (Supplementary Table S4; Supplementary Figure S3).

\section{fMRI Predictors of Clinical Response to Treatment}

We performed an analysis to look specifically for region activations at baseline fMRI capable of predicting treatment responders at week 8 . We found that increased baseline activation during painful stimulation in the right dorsolateral prefrontal cortex (BA 9) and reduced deactivation in the subgenual ACC and extended medial prefrontal regions were significantly associated with positive responses to treatment (measured as 50\% reductions in the HAM-D 17) (Supplementary Table S4; Supplementary Figure S3).

\section{Correlations Between Experimental Pain Ratings and fMRI Treatment Effects}

This analysis allowed us to map the relationship between experimental pain perception and brain activation in regions showing significant treatment effects in MDD. Although no significant results emerged for the unpleasantness correlation analyses, both the increase in perceived pain intensity after treatment (score change from baseline to week 8) and pain intensity scores reported at week 8 were significantly associated with brain regions modulated by treatment in MDD patients (Supplementary Table S5; Supplementary Figure S4). Specifically, (1) increases in experimental pain intensity from baseline to week 8 were associated with treatment-related activation reductions in the right frontal cortex and (2) greater pain intensity scores at week 8 were significantly associated with greater

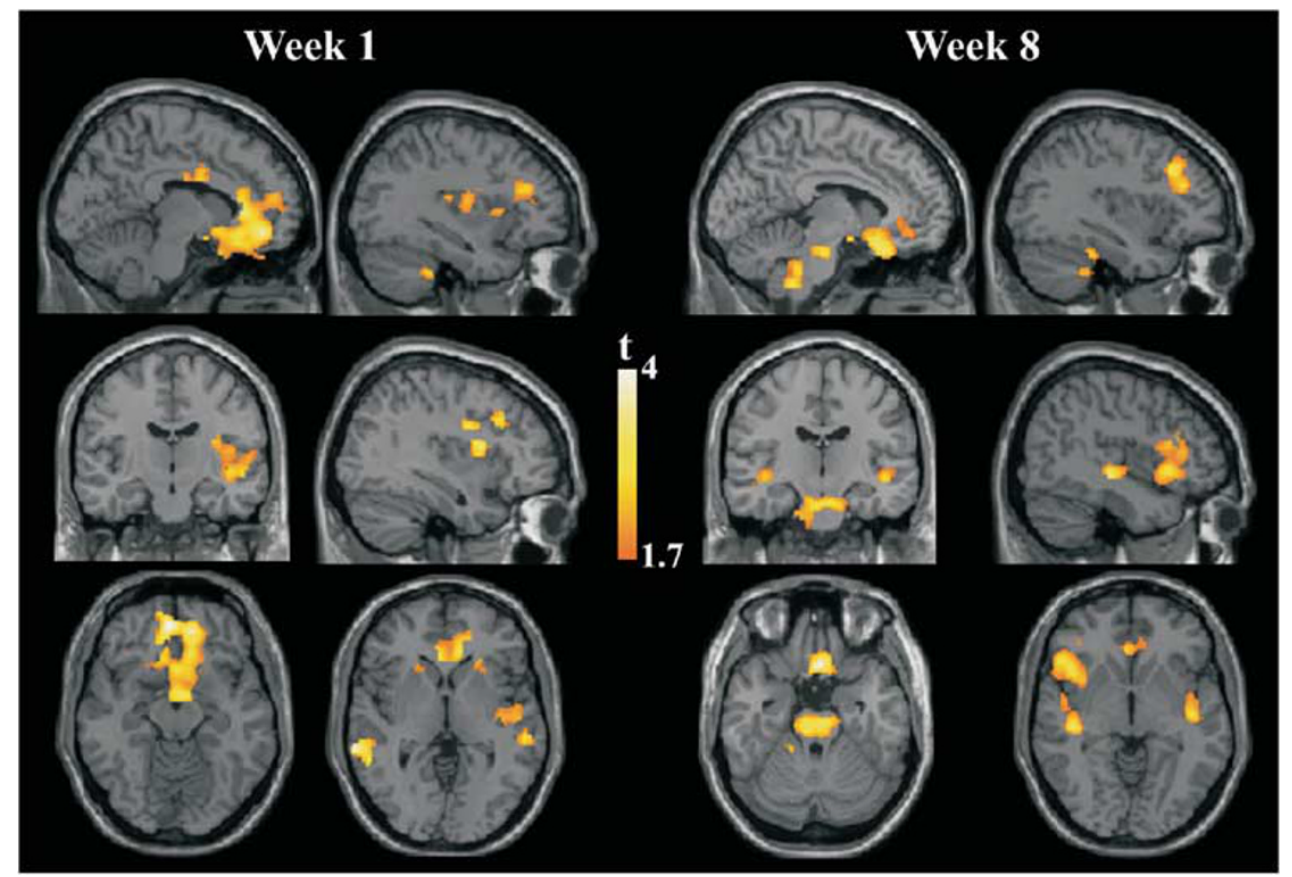

Figure 3 Group-by-time interaction effects showing significant activation reductions in the MDD group after I (baseline to I week) and 8 weeks (baseline to 8 weeks) of receiving treatment when compared with reassessment effects in the healthy control group. Images are shown in the neurological convention. Extension threshold: 200 voxels. p-Voxel level $<0.05$ uncorrected. 
subgenual ACC (and extended medial prefrontal cortex) deactivation magnitudes.

\section{DISCUSSION}

Major depressive disorder patients treated with duloxetine showed a significant reduction in fMRI pain-related activations (and enhancement of deactivations) when compared with nontreated control subjects. Relevantly, most treatment-related imaging changes occurred in regions showing altered baseline responses to pain in the patient group. Treatment-related deactivation increases in the pregenual ACC, and activation reductions in right prefrontal cortex and pons were associated with MDD symptom improvement. Pontine changes were specifically related to MDD clinical remission. Higher baseline activation in the right prefrontal cortex and lower deactivation in the subgenual ACC predicted clinical response to treatment at week 8. Remarkably, these two brain areas also showed a specific association with the paradoxical increase in experimental pain perception following treatment in the MDD group. Moreover, the treatment-related increase in experimental pain perception was significantly associated with the observed reduction in core emotional MDD symptoms.

The MDD group showed significant enhancement of baseline responses to pain within the insula-operculumbasal ganglia complex bilaterally, hippocampus, the hypothalamic region, and the surrounding anterior ventromedial prefrontal. To the best of our knowledge, only two studies have directly explored abnormal brain responses to painful stimulation in MDD patients. Our data are coincident with the results reported by Bär et al (2007) showing increased fMRI activations in MDD patients within several pain-processing regions. In another study, Strigo et al (2008) assessed pain in young adult MDD patients during a continuous performance task and again reported abnormal activations in patients showing increased responses to pain anticipatory cues in limbic and paralimbic regions, but mostly reduced activations during actual pain. Interestingly, their findings may well suggest a relevant role for attention resources in modulating brain responses to painful stimulation in MDD patients.

Our baseline analysis may provide relevant new findings by also indicating that MDD patients failed to deactivate a relatively large frontal region involving the subgenualpregenual ACC and adjacent medial prefrontal areas in response to painful stimuli. These ventromedial prefrontal structures, which are a growing focus of interest in MDD research, are normally highly active in resting-state conditions when attention is primarily self-directed and become deactivated in response to attention-demanding external stimulation (Harrison et al, 2008; Raichle et al, 2001). Interestingly, fMRI studies in MDD assessing brain responses during emotion processing, judgment and reappraisal of aversive stimuli (Grimm et al, 2009; Sheline et al, 2009), and during cognitive-executive tasks (Matthews et al, 2009; Mitterschiffthaler et al, 2008; Vasic et al, 2009; Wagner et al, 2006, 2008) have reported a failure to reduce activity in depressed patients in these medial prefrontal regions, which has been linked to symptom severity
(Grimm et al, 2009; Matthews et al, 2009). All in all, our findings, together with previous data, may reflect impaired effectiveness for patients in disengaging from self-referential processing.

We observed significant changes in brain responses to pain after 1 week of treatment manifested as greater activation reductions in treated MDD patients when compared with control subjects, mostly within areas showing abnormally enhanced responses at baseline. The complete 8-week period of duloxetine treatment was associated with significant brain activation reductions in a similar region pattern, together with additional changes in the brainstem. These late (8-week) brain functional changes were paralleled by robust clinical improvement in core and somatic MDD symptoms, which was fully accomplished up to clinical remission in a relevant proportion of patients. To the best of our knowledge, there is no previous imaging study to date assessing the effects of duloxetine on brain function. Also, this is the first fMRI study using painful stimulation as a basic neural stressor to map treatment effects on brain activation and their association with clinical outcome (one previous study used painful stimulation to assess the effects of several drug treatments on cerebral blood flow using SPECT; Graff-Guerrero et al, 2008).

Few studies have evaluated short-term effects of antidepressant treatment using neuroimaging tools. A recent SPECT study reported a broad attenuation of cerebral blood flow responses to painful stimulation in a group of MDD patients treated with different antidepressant drugs for 2 weeks (Graff-Guerrero et al, 2008). Another study using an fMRI paradigm of aversive $v s$ neutral pictures (Davidson et al, 2003) also found significant fMRI BOLD signal changes in the insular cortex after 2 weeks of treatment using the dual reuptake inhibitor venlafaxine. Both studies also reported significant, albeit mild, reductions in clinical measurements of MDD severity. Mayberg et al (2000) did not report any significant clinical responses after 1 week of fluoxetine treatment, although metabolic changes were noticed in several cortical and subcortical regions. Our data coincide with previous studies in showing detectable imaging changes at early treatment stages when the clinical effects are typically modest. The potential ability of neuroimaging for the early detection of brain changes could be useful in future drug discovery research, mainly if brain regions relevant to MDD are targeted. In our study, brain activation reductions after 1 week of duloxetine treatment included activation changes in regions already reported in the previous studies (insula, hippocampus, and basal ganglia), but also in the critical subgenual ACC and in the dorsolateral prefrontal cortex.

In contrast with the paucity of studies assessing early brain changes during MDD treatment, imaging assessment of complete treatment effects has been more comprehensive. A large number of PET and SPECT studies have provided evidence of treatment-related normalization of altered baseline patterns of brain metabolic activity in MDD patients after various treatment strategies (see recent reviews by Frewen et al, 2008; Mayberg, 2009; Padberg and George, 2009; Ressler and Mayberg, 2007; Rigucci et al, 2009; Roffman et al, 2005; Schmidt et al, 2008). Less information, however, is available as to the effects of antidepressant treatment on altered brain systems in MDD 
when specifically challenged by disease-relevant stimulation. Consistent with our results, fMRI studies using aversive visual stimulation mostly reported treatmentrelated activation reductions (in regions generally showing abnormally enhanced baseline responses) after 8 weeks of treatment with fluoxetine (Fu et al, 2004), sertraline (Sheline et al, 2001) and bupropion (Robertson et al, 2007), and after 16 weeks of cognitive behavioral therapy (Fu et al, 2008). Davidson et al (2003) additionally reported a normalization of abnormal functional deactivations in MDD patients in response to aversive visual stimulation after 8 weeks of venlafaxine treatment. All in all, taken with our own findings, these studies appear to suggest a global effect of successful treatment on restoring the equilibrium within the complete pattern of brain activation and deactivation responses to distinct types of aversive stimulation.

Research evidence suggests the participation of the subgenual ACC and surrounding medial regions in both self-referential attention (mentioned above) and in guiding behavior and mood regulation through its influence on autonomic, endocrine, and visceral functions (Drevets et al, 2008b; Paus, 2001; Price, 1999). The main afferents to this neuroanatomic region come from the amygdala, ventral striatum, thalamus, and brainstem monoamine nuclei (Paus, 2001). The subgenual ACC and extended medial prefrontal regions, in turn, send dense projections to the periaqueductal gray matter and, especially, to the hypothalamus, where these projections synapse with neurons projecting to the brainstem and spinal autonomic centers (Barbas et al, 2003). Structural and functional abnormalities of the subgenual ACC have been extensively reported in depressive patients (reviewed by Drevets et al, 2008b), and have been frequently associated with MDD symptom severity (Chen et al, 2007; Greicius et al, 2007; Matthews et al, 2009). Previous research has shown the capacity of a wide variety of antidepressant treatment strategies to modulate and normalize functional alterations in the subgenual-pregenual ACC and extended regions within the medial frontal cortex (for relevant examples, see Drevets et al, 2002; Mayberg et al, 2000, 2005; Nahas et al, 2007). This study shows the association of duloxetine treatment with significant changes in subgenual ACC and adjacent areas involving the normalization of altered baseline responses to aversive painful stimulation. The observed pattern of functional changes suggests that our imaging strategy is also useful in assessing this critical region in MDD.

Symptomatic improvement after 8 weeks of duloxetine treatment was associated with treatment-related activation reductions in specific regions and with a paradoxical enhancement in subjective perception of experimental pain. Importantly, functional changes in the right prefrontal cortex, which has been specifically involved in mediating negative affect particularly in the context of MDD (Davidson et al, 2002; Davidson, 2002; Liotti and Mayberg, 2001), were associated with improvement in core emotion symptoms of depression. Activation reductions in the pons were significantly correlated with improvement in somatic complaints and were specifically associated with clinical remission. In a recent study, Milak et al (2009) reported a specific relationship between baseline metabolic activity in the pons-midbrain region and clinical remission after
12 weeks of pharmacological treatment, which gives greater consistency to this pontine finding. In addition, Mayberg et al (2002) showed a pattern of metabolic changes in the pons, specifically in positive responders to fluoxetine that did not appear in the placebo responder group, which may suggest that functional changes in the region are more plausibly attributable to specific psychotropic effects of the drug.

The painful stimulation paradigm used here has successfully provided imaging biomarkers of positive clinical response to duloxetine treatment in MDD patients. Although there is no previously published study on brain functional predictors of positive clinical outcome associated with duloxetine, our findings are highly coincident with imaging literature showing the important role for the subgenualpregenual ACC and extended medial prefrontal areas and, albeit to a lesser extent, dorsolateral prefrontal regions, in predicting clinical responses to various treatment modalities in MDD (Brockmann et al, 2009; Chen et al, 2007; Davidson et al, 2003; Dougherty et al, 2003; Keedwell et al, 2010; Little et al, 2005; Mayberg et al, 1997; Mottaghy et al, 2002; Saxena et al, 2003; Siegle et al, 2006; $\mathrm{Wu}$ et al, 1999).

Interestingly, MDD patients at baseline showed a tendency to report reduced subjective experimental pain scores, an effect that was reversed after 8 weeks of treatment. MDD research has provided evidence for the paradoxical phenomena of increased somatic complaints in depressive patients paralleled by decreased pain perception during externally delivered painful stimulation on the skin (mainly thermal and electrical stimuli; Bär et al, 2003; 2005; 2007; Dickens et al, 2003; Lautenbacher et al, 1994, 1999). In contrast, MDD patients may show hyperalgesia for deep somatic pain modalities such as muscle ischemia (Bär et al, 2005). Such data may suggest an increased processing of internal somatic and visceral afferent stimulation in MDD congruent with enhanced self-focused attention that may be paralleled by a reduction of brain attentional resources destined to external stimulation, including painful stimuli. Considering the above-mentioned role of the subgenual ACC in maintaining self-focused attention, baseline deactivation reductions in this region fit well with the observed opposite tendencies found for sensitivity to internal and external pain in MDD patients. Coherently, antidepressant treatment with duloxetine was associated with normalization of the abnormally absent subgenual ACC deactivation, and with both an increase in experimental pain sensitivity and a reduction in somatic pain complaints. Moreover, a specific correlation was found at week 8 between greater deactivation magnitudes in this region and higher experimental pain ratings in MDD.

Reductions in right frontal cortex responses to pain from baseline to week 8 in MDD patients were significantly associated with both an increase in subjective experimental pain perception and a decrease in core emotional symptoms of depression. In the context of the discussed paradox, it may indeed be relevant to mention that treatment-related activation reductions (associated with subjective pain score increases) were not observed in brain regions specifically devoted to the encoding of subjective pain perception (which has been mostly attributed to primary somatosensory area, dorsal ACC, and specific portions of 
the insula; Hofbauer et al, 2001; Peyron et al, 2000; Rainville et al, 1997). Apart from the previously mentioned role of the subgenual ACC in the recovery of sensitivity to externally induced pain on the skin, the relevant role of the right prefrontal cortex in modulating - ie, reducing - pain perception in natural and experimentally modified attentional and expectation contexts (eg, placebo analgesia or distraction while performing another cognitive task) has been widely suggested in previous pain neuroimaging literature (Lieberman et al, 2004; López-Solà et al, 2010; Lorenz et al, 2003; Petrovic et al, 2000; Peyron et al, 1999; Salomons et al, 2004, 2007; Wager et al, 2004; Wiech et al, 2006, 2008b). Coherently, three studies have shown enhanced prefrontal activations associated with reduced experimental pain subjective scores in three distinct psychiatric populations, MDD, adjustment disorder and borderline personality disorder (Bär et al, 2006, 2007; Schmahl et al, 2006). Our study may further inform as to the neural basis of the inverse relationship between sensitivity to experimental pain and core emotional symptoms of depression by suggesting a crucial role for the right prefrontal cortex (and also partly the subgenual ACC) in mediating both the core antidepressant effects and the changes in subjective pain perception. The experimental animal study by Jochum et al (2007) showed, in agreement with our data, that treatment with the SSRI citalopram for 8 weeks significantly increased the sensitivity to thermal pain in anxious/ depressed rats that had a significant baseline hypoalgesia for this painful stimulation modality.

Although we used a comparison group of healthy subjects to control for task-repetition effects over time on brain activation changes, we cannot estimate the influence of placebo effects on the observed results. The absence of a placebo patient group constitutes a relevant limitation of the study, which was considered insurmountable in our clinical context on the grounds of both patient severity and the long period that would have been required without administering effective treatment. Nevertheless, the rate of clinical response and remission achieved following 8 weeks of duloxetine treatment suggest the existence of a significant antidepressant effect beyond placebo (Gupta et al, 2007). In addition, treatment-related activation changes were observed after 8 weeks of duloxetine in certain regions (pons and anterior insula) previously shown to be targeted by effective fluoxetine treatment, but not modified in positive placebo responders (Mayberg et al, 2002), thus providing our results with greater drug specificity.

It is relevant to mention that we used a relatively lenient statistical threshold (as in most studies of this type) to test for treatment effects and the correlations between brain response changes and clinical variables. Admittedly, the adopted criteria only partially control for the potential type I statistical error and we should be cautious in the overall interpretation of our results. However, it is also relevant to emphasize that our analyses were comprehensive including three assessments across time and between-group comparisons together with correlation analyses between activation changes and clinical treatment effects in the patient group. The intrastudy remarkable coherence between all the results, their consistency with previous research in MDD, and the anatomic plausibility of the findings may potentially reduce the overall risk of drawing conclusions based on false-positive data. Finally, it would have been of interest to additionally use a nonpainful reference task (such as a sadness induction paradigm) or an fMRI resting-state assessment to perform a direct comparison of the effects of duloxetine on pain-related neural responses with the effects on MDD abnormalities in brain function more primarily associated with core emotional alterations in depressive patients.

As an original approach, painful stimulation as a basic neural stressor proved to be effective in mapping brain response changes associated with antidepressant treatment and brain correlates of symptom improvement in regions of special relevance to MDD pathophysiology. Using this fMRI strategy, we assessed the effect of duloxetine in MDD for the first time by means of neuroimaging. Although placebo effects could not be accounted for, the presented results may further contribute to characterizing the functional brain changes associated with recovery from depression.

\section{ACKNOWLEDGEMENTS}

M López-Solà was supported by Grant number AP20050408 of the Spanish Ministry of Education and Science. M López-Solà and J Deus are part of the Research Group SGR 1450 of the Agency of University and Research Funding Management of the Catalan Government. Dr Harrison was supported by a National Health and Medical Research Council of Australia (NHMRC) Clinical Career Development Award (ID 628509) and an establishment grant from The Clive and Vera Ramaciotti Foundation. O ContrerasRodríguez was supported by Grant number RECODE2007I054 from the Spanish Ministry of Health. This work received a Grant from Boehringer Ingelheim Spain and Grant number SAF2007-62376 from the Spanish Ministry of Education and Science.

\section{DISCLOSURE}

All the income from Boehringer Ingelheim was used to cover part of setting and MRI expenses. None of the funding institutions had any further role in the study design; in the collection, analysis and interpretation of data; in the writing of the report; and in the decision to submit the article for publication. Marina López-Solà declares that she has received funding from the University of Barcelona. Dr Jesus Pujol declares that he has received funding from the Institut d'Alta Tecnologia-PRBB, CRC Hospital del Mar. Dr Rosa Hernández-Ribas declares that she has received funding from the Bellvitge University Hospital-IDIBELL and from the Spanish Ministry of Science and Innovation, Instituto de Salud Carlos III, Centro de Investigación en Red de Salud Mental (CIBERSAM). Dr Ben J Harrison declares that he has received funding from the National Health and Medical Research Council of Australia. Oren ContrerasRodríguez declares she has received funding from the Fundació IMIM. Dr Carles Soriano-Mas declares that he has received funding from the Institut d'Alta Tecnologia-PRBB, CRC Hospital del Mar, and from the Fundació IMIM. Dr Joan Deus declares that he has received funding from the Autonomous University of Barcelona. Hector Ortiz declares that he has received funding from the Technical University 
of Catalonia and from the General Electric Company. Dr José M Menchon declares that he has received funding from the University of Barcelona, the Bellvitge University Hospital-IDIBELL, and from the Spanish Ministry of Science and Innovation, Instituto de Salud Carlos III, Centro de Investigación en Red de Salud Mental (CIBERSAM). He has also received honoraria as a consultant from Almirall, AstraZeneca, Boehringer Ingelheim, Eli Lilly, Janssen, Lundbeck, and Wyeth. Dr Narcis Cardoner declares that he has received funding from the University of Barcelona, Bellvitge University Hospital-IDIBELL, and from the Spanish Ministry of Science and Innovation, Instituto de Salud Carlos III, Centro de Investigación en Red de Salud Mental (CIBERSAM). He has also received honoraria as a consultant from Almirall, Boehringer Ingelheim, Eli Lilly, Janssen, Lundbeck, Pfizer, and Wyeth. Dr Julio Vallejo declares that he has received funding from the University of Barcelona, the Bellvitge University Hospital-IDIBELL, and from the Spanish Ministry of Science and Innovation, Instituto de Salud Carlos III, Centro de Investigación en Red de Salud Mental (CIBERSAM).

\section{REFERENCES}

American Psychiatric Association (2000). Diagnostic and Statistical Manual of Mental Disorders 4th edn. text revision. American Psychiatric Press: Washington, DC.

Apkarian AV, Bushnell MC, Treede RD, Zubieta JK (2005). Human brain mechanisms of pain perception and regulation in health and disease. Eur J Pain 9: 463-484.

Bär KJ, Brehm S, Boettger MK, Boettger S, Wagner G, Sauer H (2005). Pain perception in major depression depends on pain modality. Pain 117: 97-103.

Bär KJ, Brehm S, Boettger MK, Wagner G, Boettger S, Sauer H (2006). Decreased sensitivity to experimental pain in adjustment disorder. Eur J Pain 10: 467-471.

Bär KJ, Greiner W, Letsch A, Köbele R, Sauer H (2003). Influence of gender and hemispheric lateralization on heat pain perception in major depression. J Psychiatr Res 37: 345-353.

Bär KJ, Wagner G, Koschke M, Boettger S, Boettger MK, Schlösser $\mathrm{R}$ et al (2007). Increased prefrontal activation during pain perception in major depression. Biol Psychiatry 62: $1281-1287$.

Bair MJ, Robinson RL, Katon W, Kroenke K (2003). Depression and pain comorbidity: a literature review. Arch Intern Med 163: 2433-2445.

Barbas H, Saha S, Rempel-Clower N, Ghashghaei T (2003). Serial pathways from primate prefrontal cortex to autonomic areas may influence emotional expression. BMC Neurosci 10: 4-25.

Blier P, Abbott FV (2001). Putative mechanisms of action of antidepressant drugs in affective and anxiety disorders and pain. J Psychiatry Neurosci 26: 37-43.

Brockmann H, Zobel A, Joe A, Biermann K, Scheef L, Schuhmacher A et al (2009). The value of HMPAO SPECT in predicting treatment response to citalopram in patients with major depression. Psychiatry Res 173: 107-112.

Chen CH, Ridler K, Suckling J, Williams S, Fu CH, Merlo-Pich E et al (2007). Brain imaging correlates of depressive symptom severity and predictors of symptom improvement after antidepressant treatment. Biol Psychiatry 62: 407-414.

Cleeland CS, Ryan KM (1994). Pain assessment: global use of the Brief Pain Inventory. Ann Acad Med Singapore 23: 129-138.

Davidson RJ (2002). Anxiety and affective style: role of prefrontal cortex and amygdala. Biol Psychiatry 51: 68-80.
Davidson RJ, Irwin W, Anderle MJ, Kalin NH (2003). The neural substrates of affective processing in depressed patients treated with venlafaxine. Am J Psychiatry 160: 64-75.

Davidson RJ, Pizzagalli D, Nitschke JB, Putnam K (2002). Depression: perspectives from affective neuroscience. Annu Rev Psychol 53: 545-574.

Dickens C, McGowan L, Dale S (2003). Impact of depression on experimental pain perception: a systematic review of the literature with meta-analysis. Psychosom Med 65: 369-375.

Dougherty DD, Weiss AP, Cosgrove GR, Alpert NM, Cassem EH, Nierenberg AA et al (2003). Cerebral metabolic correlates as potential predictors of response to anterior cingulotomy for treatment of major depression. J Neurosurg 99: 1010-1017.

Drevets WC (2000). Neuroimaging studies of mood disorders. Biol Psychiatry 48: 813-829.

Drevets WC, Bogers W, Raichle ME (2002). Functional anatomical correlates of antidepressant drug treatment assessed using PET measures of regional glucose metabolism. Eur Neuropsychopharmacol 12: 527-544.

Drevets WC, Price JL, Furey ML (2008a). Brain structural and functional abnormalities in mood disorders: implications for neurocircuitry models of depression. Brain Struct Funct 213: 93-118.

Drevets WC, Savitz J, Trimble M (2008b). The subgenual anterior cingulate cortex in mood disorders. CNS Spectr 13: 663-681.

First MB, Spitzer RL, Gibbon M, Williams JBW (1997). Structured Clinical Interview for DSM-IV Axis I Disorders- Clinician Version $(S C I D-C V)$. American Psychiatric Press: Washington, DC.

Frewen PA, Dozois DJ, Lanius RA (2008). Neuroimaging studies of psychological interventions for mood and anxiety disorders: empirical and methodological review. Clin Psychol Rev 28: 228-246.

Fu CH, Williams SC, Cleare AJ, Brammer MJ, Walsh ND, Kim J et al (2004). Attenuation of the neural response to sad faces in major depression by antidepressant treatment: a prospective, event-related functional magnetic resonance imaging study. Arch Gen Psychiatry 61: 877-889.

Fu CH, Williams SC, Cleare AJ, Scott J, Mitterschiffthaler MT, Walsh ND et al (2008). Neural responses to sad facial expressions in major depression following cognitive behavioral therapy. Biol Psychiatry 64: 505-512.

Graff-Guerrero A, Pellicer F, Mendoza-Espinosa Y, MartínezMedina P, Romero-Romo J, de la Fuente Sandoval C (2008). Cerebral blood flow changes associated with experimental pain stimulation in patients with major depression. J Affect Disord 107: 161-168.

Greicius MD, Flores BH, Menon V, Glover GH, Solvason HB, Kenna $\mathrm{H}$ et al (2007). Resting-state functional connectivity in major depression: abnormally increased contributions from subgenual cingulate cortex and thalamus. Biol Psychiatry 62: 429-437.

Grimm S, Boesiger P, Beck J, Schuepbach D, Bermpohl F, Walter M et al (2009). Altered negative BOLD responses in the defaultmode network during emotion processing in depressed subjects. Neuropsychopharmacology 34: 932-943.

Gupta S, Nihalani N, Masand P (2007). Duloxetine: review of its pharmacology, and therapeutic use in depression and other psychiatric disorders. Ann Clin Psychiatry 19: 125-132.

Guy W (ed) (1976). Clinical Global Impressions. In: ECDEU Assessment Manual for Psychopharmacology, Revised (DHEW Publication No ADM 76-338). National Institute of Mental Health: Rockville, MD. pp 218-222.

Hamilton M (1960). A rating scale for depression. J Neurol Neurosurg Psychiatry 23: 56-62.

Hamilton M (1967). The development of a scale for primary depressive illness. Br J Soc Clin Psychol 6: 278-296. 
Harrison BJ, Pujol J, López-Solà M, Hernández-Ribas R, Deus J, Ortiz $\mathrm{H}$ et al (2008). Consistency and functional specialization in the default mode brain network. Proc Natl Acad Sci USA 105: 9781-9786.

Hirschfeld RM, Mallinckrodt C, Lee TC, Detke MJ (2005). Time course of depression-symptom improvement during treatment with duloxetine. Depress Anxiety 21: 170-177.

Hofbauer RK, Rainville P, Duncan GH, Bushnell MC (2001). Cortical representation of the sensory dimension of pain. J Neurophysiol 86: 402-411.

Jochum T, Boettger MK, Wigger A, Beiderbeck D, Neumann ID, Landgraf $\mathrm{R}$ et al (2007). Decreased sensitivity to thermal pain in rats bred for high anxiety-related behaviour is attenuated by citalopram or diazepam treatment. Behav Brain Res 183: 18-24.

Keedwell PA, Drapier D, Surguladze S, Giampietro V, Brammer M, Phillips M (2010). Subgenual cingulate and visual cortex responses to sad faces predict clinical outcome during antidepressant treatment for depression. J Affect Disord 120: 120-125.

Kellner R (1987). A symptom questionnaire. J Clin Psychiatry 48: 268-274.

Lautenbacher S, Roscher S, Strian D, Fassbender K, Krumrey K, Krieg JC (1994). Pain perception in depression: relationships to symptomatology and naloxone-sensitive mechanisms. Psychosom Med 56: 345-352.

Lautenbacher S, Spernal J, Schreiber W, Krieg JC (1999). Relationship between clinical pain complaints and pain sensitivity in patients with depression and panic disorder. Psychosom Med 61: 822-827.

Lieberman MD, Cunningham WA (2009). Type I and type II error concerns in fMRI research: re-balancing the scale. Soc Cogn Affect Neurosci 4: 423-428.

Lieberman MD, Jarcho JM, Berman S, Naliboff BD, Suyenobu BY, Mandelkern $\mathrm{M}$ et al (2004). The neural correlates of placebo effects: a disruption account. Neuroimage 22: 447-455.

Liotti M, Mayberg HS (2001). The role of functional neuroimaging in the neuropsychology of depression. J Clin Exp Neuropsychol 23: $121-136$

Little JT, Ketter TA, Kimbrell TA, Dunn RT, Benson BE, Willis MW et al (2005). Bupropion and venlafaxine responders differ in pretreatment regional cerebral metabolism in unipolar depression. Biol Psychiatry 57: 220-228.

López-Solà M, Pujol J, Hernández-Ribas R, Harrison BJ, Ortiz H, Soriano-Mas C et al (2010). Dynamic assessment of the right lateral frontal cortex response to painful stimulation. Neuroimage 50: 1177-1187.

Lorenz J, Minoshima S, Casey KL (2003). Keeping pain out of mind: the role of the dorsolateral prefrontal cortex in pain modulation. Brain 126: 1079-1091.

Matthews S, Simmons A, Strigo I, Gianaros P, Yang T, Paulus M (2009). Inhibition-related activity in subgenual cingulate is associated with symptom severity in major depression. Psychiatry Res 172: 1-6.

Mayberg HS (2003). Positron emission tomography imaging in depression: a neural systems perspective. Neuroimaging Clin $\mathrm{N}$ Am 13: 805-815.

Mayberg HS (2009). Targeted electrode-based modulation of neural circuits for depression. J Clin Invest 119: 717-725.

Mayberg HS, Brannan SK, Mahurin RK, Jerabek PA, Brickman JS, Tekell JL et al (1997). Cingulate function in depression: a potential predictor of treatment response. Neuroreport 8: 1057-1061.

Mayberg HS, Brannan SK, Tekell JL, Silva JA, Mahurin RK, McGinnis S et al (2000). Regional metabolic effects of fluoxetine in major depression: serial changes and relationship to clinical response. Biol Psychiatry 48: 830-843.

Mayberg HS, Lozano AM, Voon V, McNeely HE, Seminowicz D, Hamani C et al (2005). Deep brain stimulation for treatmentresistant depression. Neuron 45: 651-660.
Mayberg HS, Silva JA, Brannan SK, Tekell JL, Mahurin RK, McGinnis S et al (2002). The functional neuroanatomy of the placebo effect. Am J Psychiatry 159: 728-737.

Milak MS, Parsey RV, Lee L, Oquendo MA, Olvet DM, Eipper F et al (2009). Pretreatment regional brain glucose uptake in the midbrain on PET may predict remission from a major depressive episode after three months of treatment. Psychiatry Res 173: 63-70.

Mitterschiffthaler MT, Williams SC, Walsh ND, Cleare AJ, Donaldson C, Scott J et al (2008). Neural basis of the emotional Stroop interference effect in major depression. Psychol Med 38: 247-256.

Mottaghy FM, Keller CE, Gangitano M, Ly J, Thall M, Parker JA et al (2002). Correlation of cerebral blood flow and treatment effects of repetitive transcranial magnetic stimulation in depressed patients. Psychiatry Res 115: 1-14.

Moulton EA, Keaser ML, Gullapalli RP, Greenspan JD (2005). Regional intensive and temporal patterns of functional MRI activation distinguishing noxious and innocuous contact heat. J Neurophysiol 93: 2183-2193.

Nahas Z, Teneback C, Chae JH, Mu Q, Molnar C, Kozel FA et al (2007). Serial vagus nerve stimulation functional MRI in treatment resistant depression. Neuropsychopharmacology 32: $1649-1660$

Nemeroff CB, Schatzberg AF, Goldstein DJ, Detke MJ, Mallinckrodt $\mathrm{C}, \mathrm{Lu} \mathrm{Y}$ et al (2002). Duloxetine for the treatment of major depressive disorder. Psychopharmacol Bull 36: 106-132.

Padberg F, George MS (2009). Repetitive transcranial magnetic stimulation of the prefrontal cortex in depression. Exp Neurol 219: 2-13.

Paus T (2001). Primate anterior cingulate cortex: where motor control, drive and cognition interface. Nat Rev Neurosci 2: $417-424$

Petrovic P, Petersson KM, Ghatan PH, Stone-Elander S, Ingvar M (2000). Pain-related cerebral activation is altered by a distracting cognitive task. Pain 85: 19-30.

Peyron R, García-Larrea L, Grégoire MC, Costes N, Convers P, Lavenne $\mathrm{F}$ et al (1999). Haemodynamic brain responses to acute pain in humans: sensory and attentional networks. Brain 122: $1765-1780$.

Peyron R, Laurent B, García-Larrea L (2000). Functional imaging of brain responses to pain. A review and meta-analysis (2000). Neurophysiol Clin 30: 263-288.

Price DD (2000). Psychological and neural mechanisms of the affective dimension of pain. Science 288: 1769-1772.

Price JL (1999). Prefrontal cortical networks related to visceral function and mood. Ann NY Acad Sci 877: 383-396.

Price JL, Drevets WC (2010). Neurocircuitry of mood disorders. Neuropsychopharmacology 35: 192-216.

Pujol J, López-Solà M, Ortiz H, Vilanova JC, Harrison BJ, Yücel $\mathrm{M}$ et al (2009). Mapping brain response to pain in fibromyalgia patients using temporal analysis of FMRI. PLoS One 4: e5224.

Raichle ME, MacLeod AM, Snyder AZ, Powers WJ, Gusnard DA, Shulman GL (2001). A default mode of brain function. Proc Natl Acad Sci USA 98: 676-682.

Rainville P, Duncan GH, Price DD, Carrier B, Bushnell MC (1997). Pain affect encoded in human anterior cingulate but not somatosensory cortex. Science 277: 968-971.

Regier DA, Myers JK, Kramer M, Robins LN, Blazer DG, Hough RL et al (1984). The NIMH Epidemiologic Catchment Area program. Historical context, major objectives, and study population characteristics. Arch Gen Psychiatry 41: 934-941.

Ressler KJ, Mayberg HS (2007). Targeting abnormal neural circuits in mood and anxiety disorders: from the laboratory to the clinic. Nat Neurosci 10: 1116-1124.

Rigucci S, Serafini G, Pompili M, Kotzalidis GD, Tatarelli R (2009). Anatomical and functional correlates in major depressive 
disorder: the contribution of neuroimaging studies. World J Biol Psychiatry 9: 1-16.

Robertson B, Wang L, Diaz MT, Aiello M, Gersing K, Beyer J et al (2007). Effect of bupropion extended release on negative emotion processing in major depressive disorder: a pilot functional magnetic resonance imaging study. J Clin Psychiatry 68: 261-267.

Roffman JL, Marci CD, Glick DM, Dougherty DD, Rauch SL (2005). Neuroimaging and the functional neuroanatomy of psychotherapy. Psychol Med 35: 1385-1398.

Salomons TV, Johnstone T, Backonja MM, Davidson RJ (2004). Perceived controllability modulates the neural response to pain. J Neurosci 24: 7199-7203.

Salomons TV, Johnstone T, Backonja MM, Shackman AJ, Davidson RJ (2007). Individual differences in the effects of perceived controllability on pain perception: critical role of the prefrontal cortex. J Cogn Neurosci 19: 993-1003.

Saxena S, Brody AL, Ho ML, Zohrabi N, Maidment KM, Baxter LR (2003). Differential brain metabolic predictors of response to paroxetine in obsessive-compulsive disorder versus major depression. Am J Psychiatry 160: 522-532.

Schmahl C, Bohus M, Esposito F, Treede RD, Di Salle F, Greffrath W et al (2006). Neural correlates of antinociception in borderline personality disorder. Arch Gen Psychiatry 63: 659-667.

Schmidt EZ, Reininghaus B, Enzinger C, Ebner C, Hofmann P, Kapfhammer HP (2008). Changes in brain metabolism after ECT-positron emission tomography in the assessment of changes in glucose metabolism subsequent to electroconvulsive therapy-lessons, limitations and future applications. J Affect Disord 106: 203-208.

Sheline YI (2003). Neuroimaging studies of mood disorder effects on the brain. Biol Psychiatry 54: 338-352.

Sheline YI, Barch DM, Donnelly JM, Ollinger JM, Snyder AZ, Mintun MA (2001). Increased amygdale response to masked emotional faces in depressed subjects resolves with antidepressant treatment: an fMRI study. Biol Psychiatry 50: 651-658.

Sheline YI, Barch DM, Price JL, Rundle MM, Vaishnavi SN, Snyder AZ et al (2009). The default mode network and selfreferential processes in depression. Proc Natl Acad Sci USA 106: 1942-1947.

Shelton RC, Prakash A, Mallinckrodt CH, Wohlreich MM, Raskin J, Robinson MJ et al (2007). Patterns of depressive symptom response in duloxetine-treated outpatients with mild, moderate or more severe depression. Int J Clin Pract 61: 1337-1348.

Siegle GJ, Carter CS, Thase ME (2006). Use of FMRI to predict recovery from unipolar depression with cognitive behavior therapy. Am J Psychiatry 163: 735-738.

Strigo IA, Simmons AN, Matthews SC, Craig AD, Paulus MP (2008). Association of major depressive disorder with altered functional brain response during anticipation and processing of heat pain. Arch Gen Psychiatry 65: 1275-1284.

Trivedi MH, Desaiah D, Ossanna MJ, Pritchett YL, Brannan SK, Detke MJ (2008). Clinical evidence for serotonin and norepinephrine reuptake inhibition of duloxetine. Int Clin Psychopharmacol 23: 161-169.

Vasic N, Walter H, Sambataro F, Wolf RC (2009). Aberrant functional connectivity of dorsolateral prefrontal and cingulate networks in patients with major depression during working memory processing. Psychol Med 39: 977-987.

Wager TD, Rilling JK, Smith EE, Sokolik A, Casey KL, Davidson RJ et al (2004). Placebo-induced changes in FMRI in the anticipation and experience of pain. Science 303: 1162-1167.

Wagner G, Koch K, Schachtzabel C, Reichenbach JR, Sauer H, Schlösser RG (2008). Enhanced rostral anterior cingulate cortex activation during cognitive control is related to orbitofrontal volume reduction in unipolar depression. J Psychiatry Neurosci 33: $199-208$.

Wagner G, Sinsel E, Sobanski T, Köhler S, Marinou V, Mentzel HJ et al (2006). Cortical inefficiency in patients with unipolar depression: an event-related FMRI study with the Stroop task. Biol Psychiatry 59: 958-965.

Wiech K, Farias M, Kahane G, Shackel N, Tiede W, Tracey I (2008b). An fMRI study measuring analgesia enhanced by religion as a belief system. Pain 139: 467-476.

Wiech K, Kalisch R, Weiskopf N, Pleger B, Stephan KE, Dolan RJ (2006). Anterolateral prefrontal cortex mediates the analgesic effect of expected and perceived control over pain. J Neurosci 26: 11501-11509.

Wiech K, Ploner M, Tracey I (2008a). Neurocognitive aspects of pain perception. Trends Cogn Sci 12: 306-313.

World Health Organization (2001). The world health report. http://www.who.int; Chap 2,4.

Wu J, Buchsbaum MS, Gillin JC, Tang C, Cadwell S, Wiegand M et al (1999). Prediction of antidepressant effects of sleep deprivation by metabolic rates in the ventral anterior cingulate and medial prefrontal cortex. Am J Psychiatry 156: 1149-1158.

Supplementary Information accompanies the paper on the Neuropsychopharmacology website (http://www.nature.com/npp) 